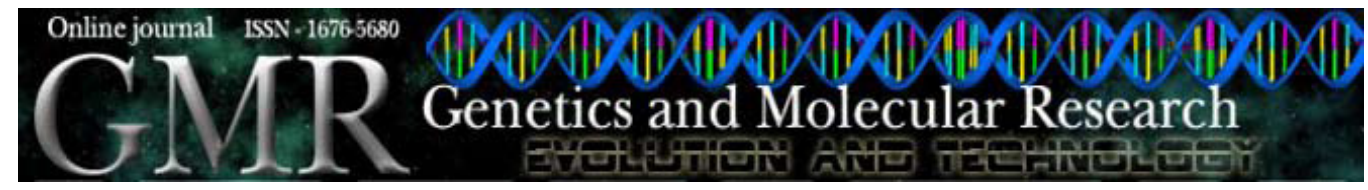

\title{
Relationship between glutathione S-transferase P1 polymorphisms and chronic obstructive pulmonary disease in a Tunisian population
}

\author{
R. Lakhdar ${ }^{1}$, S. Denden ${ }^{1}$, J. Knani ${ }^{2}$, N. Leban ${ }^{1}$, H. Daimi ${ }^{1}$, M. Hassine ${ }^{3}$, \\ G. Lefranc ${ }^{4}$, J. Ben Chibani ${ }^{1}$ and A. Haj Khelil ${ }^{1}$ \\ ${ }^{1}$ Biochemistry and Molecular Biology Laboratory, \\ Faculty of Pharmacy, Monastir, Tunisia \\ ${ }^{2}$ Pulmonology Department, CHU Tahar Sfar, Mahdia, Tunisia \\ ${ }^{3}$ Haematology Laboratory, Faculty of Pharmacy and CHU Fattouma Bourguiba, \\ Monastir, Tunisia \\ ${ }^{4}$ Institute of Human Genetics and Montpellier 2 University, France \\ Corresponding author: R. Lakhdar \\ E-mail: lakhdarramzi@yahoo.fr
}

Genet. Mol. Res. 9 (2): 897-907 (2010)

Received January 18, 2010

Accepted February 19, 2010

Published May 11, 2010

DOI 10.4238/vol9-2gmr770

\begin{abstract}
Chronic obstructive pulmonary disease (COPD) is a multifactorial disease with possible genetic predisposition and involvement of various environmental factors. Several candidate genes have been reported as potentially associated with this lung disease. The glutathione S-transferase P1 gene (GSTP1) was proposed to be involved in susceptibility to develop COPD. It belongs to the GST family, which is a group of phase II enzymes that catalyze the glutathione conjugation of many endogenous and exogenous electrophilic compounds, such as carcinogens, therapeutic drugs, environmental toxins, and oxidative stress products. We conducted a case-control study to investigate genetic polymorphisms of this enzyme [exon 5 (Ile105Val) and exon 6 (Ala114Val)] in 234 unrelated COPD cases and 182 healthy controls from a Tunisian population. Genotyping was carried out using polymerase chain reaction and restriction fragment length polymorphism methods. GSTP1 Ala114/
\end{abstract}


Val114 and Val114/Val114 genotypes were not found in either patients or healthy controls. However, there were differences in the distribution of various exon 5 GSTP1 genotypes between COPD patients and healthy controls. GSTP1 Val105/Val105 was significantly more common in patients compared to controls $(\mathrm{OR}=2.67 ; 95 \% \mathrm{CI}=1.45-4.92 ; \mathrm{P}$ $=0.0013)$. Multivariate logistic regression analysis confirmed a significant relationship between the mutant genotype and COPD $(\mathrm{OR}=2.58$; $95 \% \mathrm{CI}=1.31-5.09 ; \mathrm{P}=0.026$ ), after adjustment for classic risk factors. Analysis of variance showed no correlation between age, body-mass index, pack-years, percentage of predicted FEV1 values, and any of the GSTP1 genotypes. We conclude that subjects with GSTP1 Val105 allele are at higher risk of COPD.

Key words: Chronic obstructive pulmonary disease; Genetic polymorphism; Glutathione S-transferase

\section{INTRODUCTION}

Chronic obstructive pulmonary disease (COPD) is one of the most important respiratory causes of chronic morbidity and mortality throughout the world (Pauwels and Rabe, 2004). Currently, COPD ranks fifth among the leading causes of death (World Health Organization, 2002), and further increases in its prevalence and mortality are expected in the near future (Murray and Lopez, 1997). It is defined by the Global Initiative for Chronic Obstructive Lung Disease (GOLD, 2006) as a "disease state characterized by airflow limitation that is not fully reversible. The airflow limitation is usually both progressive and associated with an abnormal inflammatory response of the lungs to the noxious particles or gases".

As it is one of the most important risk factors for all chronic diseases, cigarette smoking is the major risk factor for COPD. Indeed, a single puff of a cigarette contains 1017 free radicals and about 4000 substrates, including carcinogenic agents, volatile aldehydes and hydrogen cyanide. These compounds accumulate in the epithelial lining fluid and may continue to produce reactive oxygen species, which could be possible causative agents of COPD. While active cigarette smoking is clearly important, only $25 \%$ of continuous smokers were found to develop COPD (Lokke et al., 2006), suggesting that individual susceptibility or genetic factors may play a role.

Several candidate genes such as $\alpha$-1-antitrypsin $(A A T)$, tumor necrosis factor $\alpha$ ( TNF- $\alpha$ ), heme oxygenase-1 (HMOX), cytochrome P450, and microsomal epoxide hydrolase $(m E P H X)$ that could be involved in the development of COPD were investigated. Among the genes that contribute to xenobiotic metabolism and susceptibility to COPD, the glutathione S-transferase (GST) gene family is one of the most studied in diverse human populations.

GST is a family of enzymes comprising 16 genes in six subfamilies [alpha (GSTA), $\mathrm{mu}$ (GSTM), omega (GSTO), pi (GSTP), theta (GSTT), and zeta (GSTZ)] that are involved in the detoxification of electrophilic intermediates, as well as of lipid peroxidation produced by 
reactive oxygen species (Strange et al., 2001; Nebert and Vasiliou, 2004).The GSTM1, T1 and P1 enzymes are expressed in lung tissues (Eaton and Bammler, 1999), where the last isoform was found to be mainly present in the respiratory tract (Cantlay et al., 1994). These GST are known to be polymorphic, and allelic variants show differences in catalytic activity.

Here, we considered the relationship between the glutathione S-transferase P1 (GSTP1) gene and COPD.

GSTP1 shows a single nucleotide polymorphism in exon 5, which results in a substitution of isoleucine (Ile) by valine (Val) at amino acid position 105 and also in exon 6 changing alanine (Ala) to valine at amino acid position 114 (Board et al., 1989). The GSTP1 Ile105Val substitution is located near the substrate-binding site, leading to a different enzyme activity depending on the type of chemical reaction (Johansson et al., 1998). Studies have reported a controversial influence of these polymorphisms in detoxification. Some investigations suggested a decrease in enzyme activity when the Ile105Val substitution occurred (Zimniak et al., 1994; Watson et al., 1998), whereas in other studies it has been demonstrated that the mutant allele (105Val) is more active in detoxification reactions compared to the homozygous wild type (105Ile) (Hu et al., 1997; Sundberg et al., 1998).

The association between the GSTP1 gene and COPD has been investigated in numerous studies. The data remain inconsistent (Harries et al., 1997; Ishii et al., 1999; Cheng et al., 2004; Rodríguez et al., 2005).

In the present study, we attempted to analyze the frequencies of Ile105Val and Ala114Val polymorphisms in the general population of our area, and to compare it with that of a sample of individuals with COPD. We assessed the correlation of GSTP1 genotypes with clinical and functional parameters of COPD, and we also studied the relationship between these genotypes and COPD susceptibility after adjustment for other risk factors: age, gender, body mass index (BMI), smoking status, and pack-years. For all these purposes, a case control study was designed.

\section{MATERIAL AND METHODS}

\section{Study design and inclusion criteria}

Our hospital-based case control study was carried out between January 2007 and December 2008 in groups of patients with different stages of COPD and in controls of Tunisian origin. The involved cases and healthy controls were unrelated. The demographic characteristics of the study subjects are summarized in Table 1.

Two hundred and thirty-four patients were recruited from the pulmonology service of CHU Tahar Sfar in Mahdia, Tunisia. All patients satisfied the clinical criteria of COPD set down in the Global Strategy for Obstructive Lung Disease (GOLD, 2006) guidelines. The detailed information of patients is presented in Table 2.

Inclusion criteria for COPD are the following: chronic airway symptoms and signs such as coughing, breathlessness, wheezing, and chronic airway obstruction, defined as a forced expiratory volume in $1 \mathrm{~s}\left(\mathrm{FEV}_{1}\right)$ /forced vital capacity (FVC) of $<70 \%$ and an $\mathrm{FEV}_{1}$ of $<80 \%$ of the predicted values from spirometric data, and $\mathrm{FEV}_{1}$ reversibility of $<12 \%$ of prebronchodilator $\mathrm{FEV}_{1}$ after inhalation of $200 \mathrm{mg}$ salbutamol.

COPD phenotype exploration was based on chest radiographic and high-resolution 
computerized tomography density findings. The patients with bronchial asthma were excluded on the basis of reversibility of airflow obstruction.

The control group contained 182 healthy subjects; all were recruited from a blood donor cohort from the central area of Tunisia. Individuals with respiratory diseases or any familial history of lung disease were excluded. All control subjects exhibited normal pulmonary function $\left(\mathrm{FEV}_{1} / \mathrm{FVC}>70 \%\right.$ and $\mathrm{FEV}_{1}>80 \%$ predicted). Hospital Ethics Committee approval and informed consent were obtained.

\section{DNA preparation}

Venous blood was collected in EDTA tubes, and genomic DNA was extracted from frozen specimens and leukocytes separated from whole blood using a standard proteinase Kphenol-chloroform protocol (Dsavis et al., 1986).

\section{PCR restriction fragment length polymorphism analysis of GSTP1 gene}

Polymerase chain reaction (PCR)-based restriction fragment length polymorphism (RFLP) was used to examine the polymorphisms of the GSTP1 gene. Genotyping was carried out using the method of Ishii et al. (1999) with slight modification. For both exon 5 and exon 6, genomic DNA (20 ng) was amplified using a Mastercycler personal thermal cycler (Eppendorf, Germany) in a $25-\mu \mathrm{L}$ reaction mixture containing $1.5 \mathrm{mM} \mathrm{MgCl}_{2}, 1 \mu \mathrm{M}$ of each primer, $0.2 \mathrm{mM}$ deoxyribonucleoside triphosphate (dNTP) and $0.5 \mathrm{IU}_{\text {GoTaq }}{ }^{\circledR}$ Flexi DNA polymerase (Promega, USA). The primers 5'-GTAGTTTGCCCAAGGTCAAG-3' and 5'-AGCCACCTGAGGGGTAAG-3' were used for the amplification of exon 5.

The GSTP1 Ile105-Val105 substitution genotype was determined using an initial denaturation for $10 \mathrm{~min}$ at $95^{\circ} \mathrm{C}$, followed by 35 cycles of denaturation at $95^{\circ} \mathrm{C}$ for $30 \mathrm{~s}$, annealing at $58^{\circ} \mathrm{C}$ for $30 \mathrm{~s}$ and extension at $72^{\circ} \mathrm{C}$ for $1 \mathrm{~min}$. A final step of elongation was performed at $72^{\circ} \mathrm{C}$ for $10 \mathrm{~min}$. After enzyme digestion with Alw26I (Fermentas, Germany) at $37^{\circ} \mathrm{C}$ for 2 $\mathrm{h}$, the homozygous wild genotype yielded two bands, 329 and $104 \mathrm{bp}$, while the homozygous mutant genotype yielded two bands of 222 and 107/104 bp. The fragments were resolved on an ethidium bromide-stained $2 \%$ agarose gel and transilluminated with UV light.

The two variant alleles in exon 6 were also differentiated by RFLP. The DNA of each sample was subjected to PCR amplification with the following primers: 5'-GGGAGCAAGCAGAGGAGAAT-3' and 5'-CAGGTTGTAGTCAGCGAAGGAG-3'.

The amplification steps consisted of an initial denaturation step at $95^{\circ} \mathrm{C}$ for $10 \mathrm{~min}, 35$ cycles of $95^{\circ} \mathrm{C}$ for $30 \mathrm{~s}, 62^{\circ} \mathrm{C}$ for $30 \mathrm{~s}$, and $72^{\circ} \mathrm{C}$ for $1 \mathrm{~min}$, followed by an elongation step at $72^{\circ} \mathrm{C}$ for $5 \mathrm{~min}$.

The restriction enzyme AciI (Fermentas, Germany) was then used to digest the PCR product, which was then, together with the DNA ladder, visualized on a $\%$ agarose gel. RFLP products were classified as Ala/Ala (predominant homozygote), Ala/Val (heterozygote) and $\mathrm{Val} / \mathrm{Val}$ (rare homozygote). The wild-type genotype showed 247-, 118- and 55-bp fragments, while the mutant genotype showed 365- and 55-bp fragments.

\section{Statistical analysis}

The SPSS for Windows version 10 software was used in all analyses. Hardy- 
Weinberg equilibrium of genotype distribution in cases and controls was evaluated by calculating $\chi^{2}$ and $\mathrm{P}$ values. Differences in allele distribution and allele frequencies among the groups were examined for statistical significance by the Pearson $\chi^{2}$ test. Odds ratios (OR) with their corresponding $95 \%$ confidence intervals (CI) were calculated. The $\chi^{2}$ test was again used to compare gender, smoking status and geographic origin between the two groups. Demographic data and spirometric parameters are presented as means \pm standard deviation. Age, smoking index expressed as pack-years (number of cigarettes smoked per day x number of years smoked/20) were compared using the unpaired Student $t$-test. Analysis of variance was carried out to evaluate clinical and functional characteristics of patients according to different genotypes of exon 5 GSTP1 gene. Logistic regression was performed to estimate $\mathrm{OR}$ and $95 \% \mathrm{CI}$ of COPD risk factors. $\mathrm{P}<0.05$ was considered to be statistically significant.

\section{RESULTS}

\section{Characteristics of the population studied}

Table 1 presents the characteristics of the study population. A total of 234 COPD patients and 182 healthy controls were enrolled for this case-control study. There was no significant difference between patients and controls in terms of gender (male:female ratio $=222: 12$ vs 173:9) and age (mean age $=61.75 \pm 13.96$ vs $56.43 \pm$ 7.03). BMI was similar in both groups $(\mathrm{P}=0.48)$, as well as pack-years of cigarette smoking $(\mathrm{P}=0.11)$.

\begin{tabular}{|c|c|c|c|}
\hline Demographic characteristic & COPD patients $(\mathrm{N}=234)$ & Controls $(\mathrm{N}=182)$ & $\mathrm{P}$ \\
\hline Age (years, means \pm SD) & $61.75 \pm 13.96$ & $56.43 \pm 7.03$ & $0.18^{\mathrm{a}}$ \\
\hline Gender (male:female) & $222: 12$ & 173:9 & $0.92^{\mathrm{b}}$ \\
\hline BMI (means \pm SD) & $25.3 \pm 6.7$ & $24.1 \pm 5.2$ & $0.48^{\mathrm{a}}$ \\
\hline \multicolumn{4}{|l|}{ Smoking status } \\
\hline Never & 15 & 13 & \\
\hline Ex & 102 & 63 & \\
\hline Current & 117 & 106 & $0.17^{\mathrm{b}}$ \\
\hline Pack-years (means \pm SD) & $51.76 \pm 29.35$ & $47.58 \pm 26.42$ & $0.11^{\mathrm{a}}$ \\
\hline \multicolumn{4}{|l|}{ Geographic origin in Tunisia } \\
\hline North & 0 & 4 & \\
\hline Center & 234 & 178 & \\
\hline South & 0 & 0 & $0.21^{\mathrm{b}}$ \\
\hline
\end{tabular}

BMI: body mass index, weight $(\mathrm{kg}) /(\text { height }(\mathrm{m}))^{2}$. Pack-years: (number of cigarettes smoked per day x number of

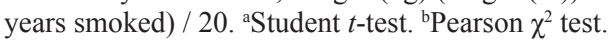

The patient group consisted of $54.27 \%$ chronic bronchitis and $45.72 \%$ emphysema (centrolobular emphysema, panlobular emphysema). Patients with COPD were classified into 4 subgroups (I, II, III, IV) according to severity of COPD (ATS criteria): at risk, mild, moderate and severe, with $\mathrm{FEV}_{1}$ of $<35 \%$ predicted. The clinical characteristics of the patients are presented in Table 2. 


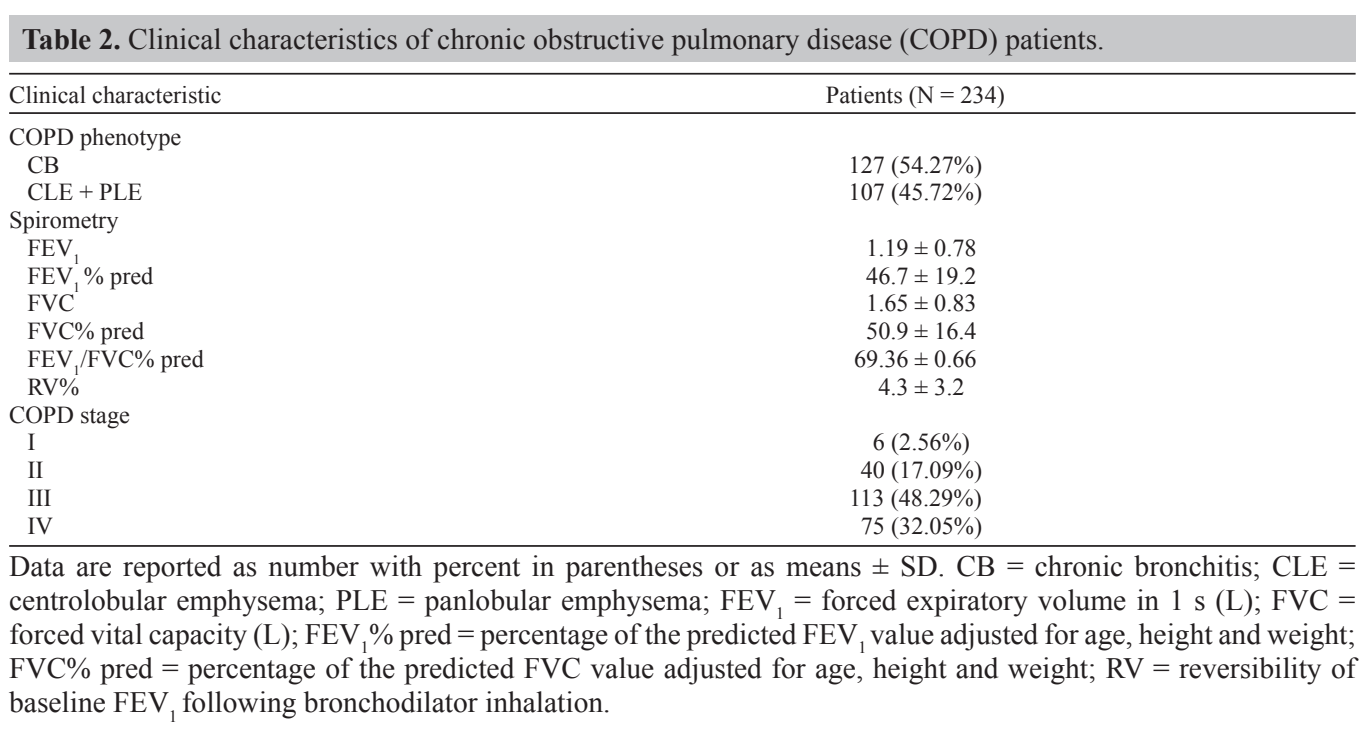

\section{GSTP1 alleles in the different study groups}

There was no deviation in the distribution of GSTP1 exon 5 polymorphism genotypes from Hardy-Weinberg equilibrium in the groups studied. The results of both exon 5 and exon 6 variants of GSTP1 evaluated comparing the COPD group with controls are listed in Table 3.

\begin{tabular}{|c|c|c|c|c|c|c|}
\hline Gene polymorphism & Genotype & Patients $(\mathrm{N}=234)$ & Controls $(\mathrm{N}=182)$ & OR & $95 \% \mathrm{CI}$ & $\mathrm{P}$ \\
\hline GSTP1 exon 5 & $\mathrm{Ile} / \mathrm{Ile}^{1}$ & $81(34.61 \%)$ & $84(46.15 \%)$ & & & \\
\hline \multirow[t]{4}{*}{ Ile105Val } & Ile/Val & $104(44.44 \%)$ & $79(43.40 \%)$ & 1.37 & $0.9-2.09$ & NS \\
\hline & $\mathrm{Val} / \mathrm{Val}$ & $49(20.94 \%)$ & $19(10.43 \%)$ & 2.67 & $1.45-4.92$ & 0.0013 \\
\hline & $\mathrm{A}(\mathrm{Ile})^{1}$ & $266(56.83 \%)$ & $247(67.85 \%)$ & & & \\
\hline & G (Val) & $202(43.16 \%)$ & 117 (32.14\%) & 1.6 & $1.2-2.13$ & 0.0011 \\
\hline GSTP1 exon 6 & Ala/Ala & $234(100 \%)$ & $182(100 \%)$ & & & \\
\hline \multirow[t]{2}{*}{ Ala114Val } & Ala/Val & 0 & 0 & - & - & - \\
\hline & $\mathrm{Val} / \mathrm{Val}$ & 0 & 0 & & & \\
\hline
\end{tabular}

Data are reported as number with percent in parentheses. NS: $\mathrm{P}>0.05 .{ }^{1}$ Reference group.

As for exon 5, homozygous Val/Val variant subjects for the GSTP1 were at increased risk of COPD $(\mathrm{OR}=2.67 ; 95 \% \mathrm{CI}=1.45-4.92)$ compared to heterozygote Ile/Val variants $(\mathrm{OR}$ $=1.37 ; 95 \% \mathrm{CI}=0.9-2.09$ ), taking the homozygote Ile/Ile variant as reference group (Table 3 ).

Our results showed that the mutant allele (Val) frequency was higher in patients than in controls and that the difference was statistically significant $(\mathrm{OR}=1.6 ; 95 \% \mathrm{CI}=1.2-2.13 ; \mathrm{P}=0.0011)$.

Regarding exon 6 polymorphism, neither the heterozygote (Ala/Val) nor the homozygous mutant (Val/Val) was found in both patient and control groups. The homozygous wild type (Ala/Ala) was the single variant existing in our present study groups. 


\section{Clinical and functional characteristics in relation to GSTP1 genotypes}

The correlation between different genotypes of exon 5 of the GSTP1 gene with clinical and functional parameters is presented in Table 4 . We found no statistically significant interactions between GSTP1 genotypes and the age of patients $(\mathrm{P}=0.176)$. There was no significant influence of these genotypes on $\mathrm{BMI}$ and pack-years $(\mathrm{P}=0.808$ and $\mathrm{P}=0.714$, respectively). In case of lung function, only the Val/Val genotype compared to Ile/Ile and Ile / Val genotypes of GSTP1 showed lower FEV1 (\% predicted) (41.23 (21.71) vs 47.05 (17.19) and 46.81 (16.55), respectively) but with no significant statistical association.

Table 4. Clinical and functional characteristics of patients with chronic obstructive pulmonary disease (COPD) according to the different genotypes of GSTP1.

\begin{tabular}{|c|c|c|c|c|}
\hline & \multicolumn{4}{|c|}{ COPD patients $(\mathrm{N}=234)$} \\
\hline & Ile/Ile $(\mathrm{N}=81)$ & Ile/Val $(\mathrm{N}=104)$ & $\mathrm{Val} / \mathrm{Val}(\mathrm{N}=49)$ & $\mathrm{P}^{\mathrm{a}}$ \\
\hline Age (years) & $59.32 \pm 13.04$ & $60.15 \pm 14.63$ & $61.28 \pm 20.74$ & 0.176 \\
\hline Gender (male:female) & $76: 5$ & $100: 4$ & $46: 3$ & 0.623 \\
\hline BMI & $24.63 \pm 5.81$ & $25.11 \pm 4.93$ & $25.95 \pm 6.27$ & 0.808 \\
\hline Pack-years & $50.06 \pm 27.38$ & $54.64 \pm 32.72$ & $51.14 \pm 28.54$ & 0.714 \\
\hline $\mathrm{FEV}_{1} \%$ pred & $47.05 \pm 17.19$ & $46.81 \pm 16.55$ & $41.23 \pm 21.71$ & 0.08 \\
\hline
\end{tabular}

${ }^{a}$ Analysis of variance. Data are reported as means \pm SD. BMI: body mass index. FEV $\%$ pred: percentage of the predicted $\mathrm{FEV}_{1}$ value adjusted for age, height and weight.

\section{Classic risk factors for COPD}

A logistic regression model was constructed to assess the predictors of CORD, with COPD as the dependent variable and gender, age, BMI, smoking status, pack-year smoking history, and GSTP1 exon 5 ValVal genotype as the independent, potentially confounding variables (Table 5). Val/Val was the only selected variable associated with $\mathrm{COPD}(\mathrm{OR}=2.58$; $95 \% \mathrm{CI}=1.31-5.09 ; \mathrm{P}=0.026)$.

\begin{tabular}{lccc}
\multicolumn{5}{l}{ Table 5. Logistic regression analysis for chronic obstructive pulmonary disease risk factors. } \\
\hline Factor & OR & $95 \%$ CI & P \\
\hline Val/Val & 2.58 & $1.31-5.09$ & 0.026 \\
Age & 1.37 & $0.64-3.72$ & 0.431 \\
Gender & 1.45 & $0.43-5.28$ & 0.468 \\
BMI & 1.10 & $0.19-4.34$ & 0.903 \\
Smoking status & 1.23 & $0.78-3.84$ & 0.337 \\
Pack-years & 1.35 & $0.85-3.61$ & 0.291 \\
\hline
\end{tabular}

BMI: body mass index.

\section{DISCUSSION}

Oxidant stress and reactive oxygen species, resulting from an oxidant/antioxidant imbalance, are believed to play an important role in the pathogenesis of COPD. Indeed, it is well known that chronic tobacco smoking is a major risk factor for the development of COPD, and a defect in the detoxification of reactive species produced by cigarette smoke may predispose smokers to airflow obstruction and emphysema. 
In the present study, we examined GSTP1 exon 5 and exon 6 genomic polymorphisms in COPD patients and healthy individuals. We provide new genotyping data of these polymorphisms and their association with susceptibility to this lung disease in a Tunisian sample.

The comparison between COPD patients and healthy controls shows that frequencies of exon 5 GSTP1 polymorphism in COPD patients differed significantly from the control group. Indeed, our results demonstrate that the homozygous mutant genotype Val/Val was 2 -fold higher in patients than in controls (20.94 vs 10.43\%). Also, we found that the frequency of the Val allele was higher in the patient group $(\mathrm{OR}=1.6 ; 95 \% \mathrm{CI}=1.2-2.13 ; \mathrm{P}=0.0011)$. We therefore suggest that the Val/Val genotype plays an important role in predisposition to COPD in the Tunisian population.

In the literature, the published studies indicate controversial results. In vitro complementary DNA expression studies suggest that the Ile105Val substitution reduces enzyme activity, and a study in human lung tissue found reduced 1-chloro-2.4 dinitrobenzene conjugation activity for GSTP1 105Val (Zimniak et al., 1994; Watson et al., 1998). In a large study (He et al., 2004) involving 1098 individuals with different degrees of lung function impairment, the results demonstrated a significant association of the 105Val allele with rapid decline in lung function in smokers with mild to moderate airflow obstruction.

Harries and colleagues (1997) reported a non-significant increase in the proportion of homozygous 105Val status among British patients with COPD as compared to healthy control subjects. This finding was confirmed by Rodríguez et al. (2005) in a Spanish population, but the authors reported that the frequency of the GSTP1 105Val polymorphism is increased in COPD patients with AAT deficiency, which is strongly associated with an increased risk of developing COPD. A combination of oxidative attack and changes in antiprotease activity could amplify the lung tissue damage in COPD. This underlines that the interactions between genes as well as environmental factors may play an important role in the development of this pathogenesis. Studies focusing on these interactions will be of great interest to better understand the mechanisms involved in the disease.

On the other hand, Ishii et al. (1999) found that the wild-type variant Ile/Ile is related to the development of COPD in the Japanese population. It is important to mention that only 53 patients with COPD and 50 control subjects were enrolled in that study and the 105Ile allelic frequency observed was lower than that reported in two previous studies (Morita et al., 1998; Katoh et al., 1999) in healthy Japanese volunteers.

In a recent meta-analysis, Smolonska and colleagues (2009) investigated 20 polymorphisms in 12 genes related to COPD pathogenesis. The authors reported that GSTP1 Ile105Val polymorphism was protective against COPD in only Asian populations $(\mathrm{OR}=0.69 ; 95 \% \mathrm{CI}=0.56-0.85)$.

In the Tunisian population, Haneni and co-authors (2007) studied 105 asthmatic children and 112 control individuals. The results revealed a protective effect of the Val/Val genotype against asthma. The influence of the GSTP1 polymorphisms in asthma is controversial. Tamer et al. (2004) has found that the GSTP1 Val/Val was more prevalent among asthmatic subjects than in the control group.

However, in another study by the same group, Calikoglu and co-workers (2006) demonstrated that the Val allele of GSTP1 may have a protective effect against the development of COPD in the Turkish population studied.

These inconsistent data could be explained by the ethnic differences, which could make a relevant contribution, and also by the variation in the selected study groups especially 
regarding the number of subjects and patients' inclusion criteria. Further investigations are necessary to draw firm conclusions.

We further analyzed the correlations between the GSTP1 genotypes and clinical and functional characteristics of COPD, and found that GSTP1 variants showed no significant association with other potential COPD risk factors (age, gender, BMI, smoking status, and packyears). The patients with GSTP1 Val/Val genotype showed lower percentage of the predicted $\mathrm{FEV}_{1}$ value than did patients with other variants but with no significant difference. This may indicate that the GSTP1 is an independent genetic risk factor for COPD. This finding was substantiated by logistic regression analysis, which demonstrated that the Val/Val genotype was in independent association with $\mathrm{COPD}(\mathrm{OR}=2.58 ; 95 \% \mathrm{CI}=1.31-5.09 ; \mathrm{P}=0.026)$.

It is generally held that GSTP1 is more abundantly expressed than other GSTs in alveoli, alveolar macrophages and respiratory bronchioles (Cantlay et al., 1994) and thus may play a crucial role in the respiratory tract. The activity of this enzyme affected by substitution at position 105 changes the substrate-binding site architecture at the protein level, giving different kinetic properties to both allelic variants (Whalen and Boyer, 1998). As a consequence of such modification in genotypes is the incomplete catabolism of toxicants due to low enzymatic activity, which may lead to oxidative stress.

It is well known that allele frequencies vary between different ethnic groups. In this study, we found that the frequencies of GSTP1 exon 5 genotypes in healthy controls were similar to those in Tunisia (Hanene et al., 2007), also close to those reported in European populations (Harries et al., 1997; Ryberg et al., 1997; van Lieshout et al., 1999; Rodríguez et al., 2005), but lower than Asiatic groups (Chan-Yeung et al., 2007). The different distribution in the 105Val allele between populations may be relevant to different GSTP1-metabolizing activities and to differences in susceptibility to specific exposure-induced diseases in different races.

As for exon 6 GSTP1 polymorphism, in our present study, we demonstrated that the mutant homozygous 114 Val allele was absent in the two groups studied. It seems that the existence of the mutant variant is very rare in the Tunisian population. According to these findings, the contribution of Ala114Val polymorphism may not be relevant in the development of COPD in our population.

The Val105/Val105 genotype distribution of GSTP1 in the present control group $(10.43 \%)$ was similar to that in another Tunisian sample (10.7\%) (Hanene et al., 2007), higher compared to Taiwanese (3\%) and European-Americans (7\%), but lower than in African-Americans $(19 \%)$ (Watson et al., 1998). The difference in frequencies of genotype may be relevant to different enzyme-metabolizing activities and types of dominant functional enzymes against oxidative stress in different races.

As for genotypes at codon 114, to our knowledge, they were assessed in Tunisia for the first time in this study. The frequency found (100\% homozygous wild-type Ala114/Ala114) was higher than in African-Americans (95\%) and European-Americans (82\%) (Watson et al., 1998), but similar compared to the Japanese population (Ishii et al., 1999). The homozygous mutant allele was not found in any population studied.

Watson et al. (1998) identified a new rare haplotype, present in two samples who were homozygous $105 \mathrm{Ile}$ and had a $114 \mathrm{Val}$ (proposed as GSTPI ${ }^{*} D$ ). There were not enough individuals in their study carrying this haplotype $(G S T P 1 * D)$ to assess if 114 valine had an independent association with the enzyme activity levels studied.

In this study, several limitations remain. First, the recruited population was moderate- 
sized and the numbers of males and females were not balanced within the two groups studied. The major population of COPD patients and chronic smokers is male in Tunisia. Therefore, it is difficult to find a balanced set of female subjects for genotype studies. Secondly, there was a difference in mean age between cases and controls. In fact, younger controls were more likely to provide a blood sample than older controls, and were thereby over sampled. However, the statistical calculation showed that there was no significant difference between the two groups in mean age, so it is unlikely that this age difference confounded the results. Additionally, age was included in all the multivariate models.

In conclusion, we found an association between GSTP1 homozygous mutant genotype (105Val/Val) and increased risk of COPD in Tunisians. Although the participation rate of COPD patients and healthy controls was considerable, further studies on a larger sample will be useful to elucidate the etiological factors of this disease.

As COPD is a complex disease, the role of multiple genes is expected. Therefore, investigating the role of combined genetic polymorphisms of phase I and II enzymes will be of great value in better understanding the mechanisms of their involvement in this disease.

\section{REFERENCES}

Board PG, Webb GC and Coggan M (1989). Isolation of a cDNA clone and localization of the human glutathione S-transferase 3 genes to chromosome bands 11q13 and 12q13-14. Ann. Hum. Genet. 53: 205-213.

Calikoglu M, Tamer L, Ates AN, Karakas S, et al. (2006). The association between polymorphic genotypes of glutathione S-transferases and COPD in the Turkish population. Biochem. Genet. 44: 307-319.

Cantlay AM, Smith CA, Wallace WA, Yap PL, et al. (1994). Heterogeneous expression and polymorphic genotype of glutathione S-transferases in human lung. Thorax 49: 1010-1014.

Chan-Yeung M, Ho SP, Cheung AH, So LK, et al. (2007). Polymorphisms of glutathione S-transferase genes and functional activity in smokers with or without COPD. Int. J. Tuberc. Lung Dis. 11: 508-514.

Cheng SL, Yu CJ, Chen CJ and Yang PC (2004). Genetic polymorphism of epoxide hydrolase and glutathione S-transferase in COPD. Eur. Respir. J. 23: 818-824.

Dsavis LG, Dibner MD and Battey JF (1986). Basic Methods in Molecular Biology. Elsevier, New York, 44-87.

Eaton DL and Bammler TK (1999). Concise review of the glutathione S-transferases and their significance to toxicology. Toxicol. Sci. 49: 156-164.

Global Initiative for Chronic Obstructive Lung Disease (GOLD) (2006). Global Strategy for the Diagnosis, Mangement and Prevention of Chronic Obstructive Pulmonary Disease. Available at [http://www.goldcopd.com]. Accessed April 14, 2009.

Hanene C, Jihene L, Jamel A, Kamel H, et al. (2007). Association of GST genes polymorphisms with asthma in Tunisian children. Mediators Inflamm. 2007: 19564. [DOI: 10.1155/2007/19564].

Harries LW, Stubbins MJ, Forman D, Howard GC, et al. (1997). Identification of genetic polymorphisms at the glutathione S-transferase Pi locus and association with susceptibility to bladder, testicular and prostate cancer. Carcinogenesis 18: 641-644.

He JQ, Connett JE, Anthonisen NR, Pare PD, et al. (2004). Glutathione S-transferase variants and their interaction with smoking on lung function. Am. J. Respir. Crit. Care Med. 170: 388-394.

Hu X, O'Donnell R, Srivastava SK, Xia H, et al. (1997). Active site architecture of polymorphic forms of human glutathione S-transferase P1-1 accounts for their enantioselectivity and disparate activity in the glutathione conjugation of 7beta,8alphadihydroxy-9alpha,10alpha-oxy-7,8,9,10-tetrahydrobenzo(a)pyrene. Biochem. Biophys. Res. Commun. 235: 424-428.

Ishii T, Matsuse T, Teramoto S, Matsui H, et al. (1999). Glutathione S-transferase P1 (GSTP1) polymorphism in patients with chronic obstructive pulmonary disease. Thorax 54: 693-696.

Johansson AS, Stenberg G, Widersten M and Mannervik B (1998). Structure-activity relationships and thermal stability of human glutathione transferase P1-1 governed by the H-site residue 105. J. Mol. Biol. 278: 687-698.

Katoh T, Kaneko S, Takasawa S, Nagata N, et al. (1999). Human glutathione S-transferase P1 polymorphism and susceptibility to smoking related epithelial cancer; oral, lung, gastric, colorectal and urothelial cancer. Pharmacogenetics 9: 165-169. 
Lokke A, Lange P, Scharling H, Fabricius P, et al. (2006). Developing COPD: a 25 year follow-up study of the general population. Thorax 61: 935-939.

Morita S, Yano M, Tsujinaka T, Ogawa A, et al. (1998). Association between genetic polymorphisms of glutathione S-transferase P1 and $\mathrm{N}$-acetyltransferase 2 and susceptibility to squamous-cell carcinoma of the esophagus. Int. J. Cancer 79: 517-520.

Murray CJ and Lopez AD (1997). Alternative projections of mortality and disability by cause 1990-2020: Global Burden of Disease Study. Lancet 349: 1498-1504.

Nebert DW and Vasiliou V (2004). Analysis of the glutathione S-transferase (GST) gene family. Hum. Genomics 1: 460-464.

Pauwels RA and Rabe KF (2004). Burden and clinical features of chronic obstructive pulmonary disease (COPD). Lancet 364: 613-620.

Rodríguez F, de la Roza C, Jardi R, Schaper M, et al. (2005). Glutathione S-transferase P1 and lung function in patients with alpha1-antitrypsin deficiency and COPD. Chest 127: 1537-1543.

Ryberg D, Skaug V, Hewer A, Phillips DH, et al. (1997). Genotypes of glutathione transferase M1 and P1 and their significance for lung DNA adduct levels and cancer risk. Carcinogenesis 18: 1285-1289.

Smolonska J, Wijmenga C, Postma DS and Boezen HM (2009). Meta-analyses on suspected chronic obstructive pulmonary disease genes: a summary of 20 years' research. Am. J. Respir. Crit. Care Med. 180: 618-631.

Strange RC, Spiteri MA, Ramachandran S and Fryer AA (2001). Glutathione-S-transferase family of enzymes. Mutat. Res. 482: 21-26.

Sundberg K, Johansson AS, Stenberg G, Widersten M, et al. (1998). Differences in the catalytic efficiencies of allelic variants of glutathione transferase P1-1 towards carcinogenic diol epoxides of polycyclic aromatic hydrocarbons. Carcinogenesis 19: 433-436.

Tamer L, Calikoglu M, Ates NA, Yildirim H, et al. (2004). Glutathione-S-transferase gene polymorphisms (GSTT1, GSTM1, GSTP1) as increased risk factors for asthma. Respirology 9: 493-498.

van Lieshout EM, Roelofs HM, Dekker S, Mulder CJ, et al. (1999). Polymorphic expression of the glutathione S-transferase P1 gene and its susceptibility to Barrett's esophagus and esophageal carcinoma. Cancer Res. 59: 586-589.

Watson MA, Stewart RK, Smith GB, Massey TE, et al. (1998). Human glutathione S-transferase P1 polymorphisms: relationship to lung tissue enzyme activity and population frequency distribution. Carcinogenesis 19: 275-280.

Whalen R and Boyer TD (1998). Human glutathione S-transferases. Semin. Liver Dis. 18: 345-358.

World Health Organization (WHO) (2002). The World Health Report 2002 - Reducing Risks, Promoting Healthy Life. Available at [http://www.who.int/whr/2002/en/]. Accessed March 3, 2009.

Zimniak P, Nanduri B, Pikula S, Bandorowicz-Pikula J, et al. (1994). Naturally occurring human glutathione S-transferase GSTP1-1 isoforms with isoleucine and valine in position 104 differ in enzymic properties. Eur. J. Biochem. 224: 893-899. 